\title{
Fashion Design: The Connective Role of Improvisation in New Learning Experiences
}

\author{
Melanie Sarantou \\ Faculty of Art and Design, University of Lapland, Finland
}

Copyright $\mathrm{O} 2018$ by authors, all rights reserved. Authors agree that this article remains permanently open access under the terms of the Creative Commons Attribution License 4.0 International License

\begin{abstract}
Improvisatory processes are considered synonymous with play, offering only second-best solutions to art and design problems. The role of improvisation in visual art processes is not widely discussed academically. This paper draws on a case study situated in Namibian art worlds to reflect on the role of improvisation in fluid and complex design and art processes. In Namibian contexts, improvisation is closely related to how artists and designers work instead of only being 'play', as improvisatory processes often respond to pressing demands and notions of having to do what needs to be done to sustain livelihoods. This paper documents and learns from the experiences and stories of Namibian art and design practitioners. The connective role of improvisation in design moments, allowing practitioners to negotiate multidirectional processes, often result in becoming unstuck in art and design processes. A holistic approach to improvisation, based on the understanding of lived experiences and actions within environments in which resources are utilised to solve design problems and build new experiences, is explored. Additionally, through improvisatory processes, learning is stimulated through new experiences that come about by utilizing the available resources within a given environment.
\end{abstract}

Keywords Fashion, Design, Art, Learning, Improvisation, Resources, Environment, Namibia

\section{Introduction}

The Sarantou and Miettinen improvisation framework emphasizes that improvisatory processes are driven by a motivation for discovery by utilizing the factors of time and thereness, judgement and evaluation, intuition, experience and skill, experimentation and risk, recognition and promisingness, process and knowing in action, change and multidirectionality [1]. Improvisers draw on experience and their acquired skills during improvisatory processes while they simultaneously gain these during the same processes. Experiences refer to sensations and perceptions that practitioners accumulate through practice, while skill is doing something well in an expertly manner through the accumulation of experience and knowledge. Improvisers also draw on intuition as emotional experiences and automatic emotional judgements [2]. Improvisation occurs through cognitive processes that happen intuitively and outside of consciousness in interplays of knowing and sensing [3]. Improvisation is underpinned by experience, traditions and risk taking during experimentation [4].

This paper is based on my fifteen years of practical design experience in the Namibian art and design 'world' [5], and a decade of fashion design lecturing at the University of Namibia. Drawing on qualitative data, my $2011 \mathrm{PhD}$ field study focused on postcolonial identities in Namibian art and design. The paper reflects on the stories and experiences of the purposively selected Namibian artist-designers who practice in this world, next to my own work, past and ongoing experiences of more than twenty-five years. The passionate narrations of the Namibian artist-designers about their improvisatory practices facilitate learning about their improvisatory art and design practices.

Additionally, this paper draws on my ongoing experiences as a researcher in global and geographically marginalized art and design settings. Over a period of five years, from 2011 until 2016, experienced craftspeople, designers and artists were interviewed to gain deeper insights into improvisatory practices and its role in their ways of work. Craftspeople, designers and artists were observed not only during my 2011 field study in Namibia, but also during an Outback South Australian artist workshop with forty-two participants, an Arctic Finnish Lapland artist workshop with twelve participants and an Arctic Kola Peninsula artist workshop in Russia with sixteen participants. Ten individuals from Namibia, twelve from South Australia, four from Lapland and three from Russia were interviewed. All general findings discussed in this article derive from data collected during these interviews and observations. 
The connective role of improvisation in invention and the management of uncertainty have been established. This paper explores a holistic understanding of improvisation through art and design processes. The connective role of improvisation in design thinking will be discussed, supplemented by the role of improvisation that is enabled through lived experiences, in shaping new learning experiences. This paper asks: 'How is learning enabled through the connective role of improvisation?'

\section{Methodology}

Ethnography was employed as both an approach and method. As an approach it focused on the holistic cultural portraits of the artists/designers to explore the behavior of individuals practicing within Namibian art worlds and thus observed within their own environments. Ethnography as method focuses on studying settings in personalized, inductive, dialogic and holistic ways to understand the settings in which real people actually live [6]. Typical of ethnography, I brought my own personal cultural background and life experiences to all the research activities [6]. Additionally, this paper employs and auto-ethnographic approach entailing self-reflection, systematic analysis and writing to explore personal experiences that are connected to lived experiences, social meanings and understandings of improvisatory art and design practices [7]. In this paper a collaborative account of improvisation that includes the experiences of both the research participants and the author, supports a break in the self-other dichotomy [8].

The paper draws on a grounded theory strategy to conduct research using methods of explication and emergence [9]. Grounded theory is based on an iterative approach and emergent conceptual analysis of data captured in the field, coding supported by memo writing, and theoretical sampling [9]. Concepts based on theory were supported by ongoing analysis of the data and adhering to a flexible approach during design research interventions. Thus, theoretical concepts are grounded in the reality of the data, giving grounded theory methodology 'theory-observation compatibility' [10]. The transferability of the results is limited by methodological reasons because ethnography and grounded theory are inevitably influenced by the positioning of the author.

However, interviews and observations with practicing designers allowed for deeper insights into the way these designer-makers worked and the role of improvisation in their making processes. Participants were not interviewed while they were involved in art and design processes, thus their reflections on their improvisatory processes stem from memories translated via storytelling. Semi-structured questions to guide the loosely constructed conversations between the interviewees and myself were used, allowing for richer data since the participants could sketch detailed stories that included personal aspects of their life and experiences; information that would otherwise have been lost in structured collection. Interviews lasted between thirty and seventy minutes and data collection methods included field notes, photographs, video recordings and their transcriptions. The participants were de-identified in the collation of the data and presentation of this research.

\section{Design and Improvisation}

Environments play an elementary role in lived experiences. Improvisation responds to stimuli within an individual's environment $[4,11]$, because to improvise is to read the affordances of the environment by exploring both the constraints and possibilities created by new conditions in the environment [4]. The term 'adhocism' suggests a divorce from rule books to instead focus on lived experiences and how things are actually done, thereby overcoming complexities through adjustment and readjustment [12]. Improvisers intimately feel the connections between separate details in processes and environments [13]. Being an 'aspect of the broader human condition', improvisation provides a site for the most fruitful kind of interdisciplinarity that is underpinned by complexities [14]. Improvisation is linked to concepts of self-organization, uncertainty and adaptation, which guide and shape lived experiences [14].

Improvisation is not a chaotic process or the idea of a second-best response to a complexity. Instead, improvisation is a system of accurate design in which moments of experimentation are guided by past experiences, allowing free variations that 'provide the requisite variety that compensates for environmental turbulence' [15]. Improvisation is the ability to deviate from learned patterns and set routines [15], thus enabling fluidity in design processes as it enables the moving from one moment in a process to the next and negotiation of ways to work during uncertainty. The use of improvisation diminishes the need for detailed contingency planning with the result of increasing thriftiness and circumventing potential waste involved in excessive planning [16].

Design thinking is an 'art of creative enquiry' [17]. The following diagram illustrates how improvisation functions in 'design thinking moments' [17]. The four design thinking moments of 'invention', 'judgement', 'connection and development', 'integration and evaluation' are proposed by Buchanan [17]. Invention stimulates processes and action that are reflected on and judged by practitioners who take informed decisions to approve or disapprove outcomes. Judgement is a crucial step to determine desirability, feasibility and viability of an outcome [17]. Evaluation is associated with the determination of value and the worth of outcomes on ethical and political levels [17]. The design thinking moment of development is driven by the urge to continue a 
process, but design thinking moments need to be connected to ensure flow. This connectedness is only possible through lived experiences and improvisation. The diagram illustrates how improvisation connects and disconnects these fluid design thinking moments, irrespective of direction, thus ensuring multidirectional flow from one design thinking moment to the next.

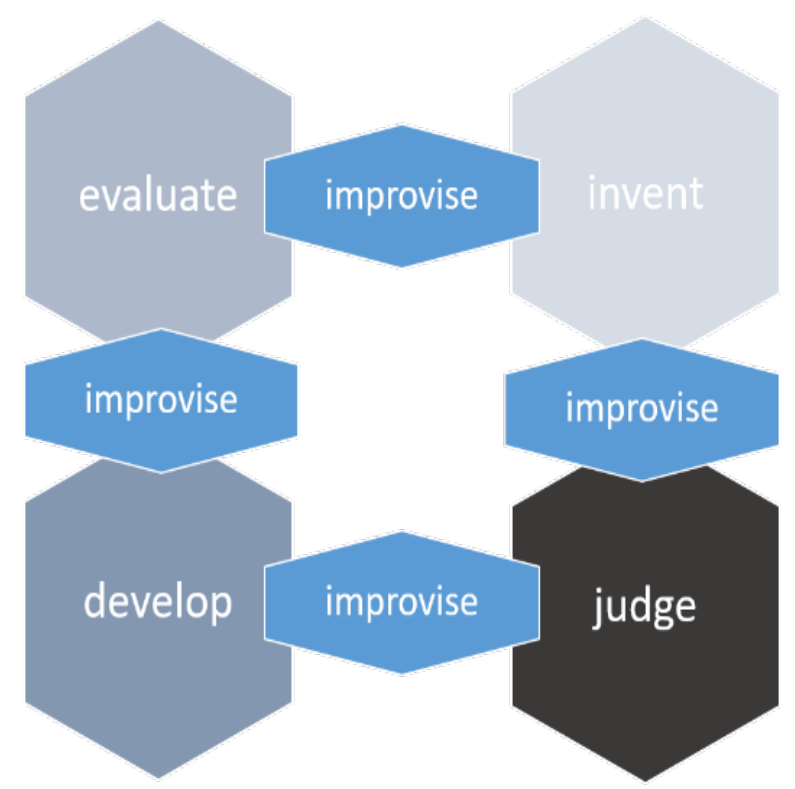

Diagram 1. This diagram is based on Buchanan's 'design moments'. Improvisation is illustrated in design thinking as a multidirectional process that enables fluidity in design processes, whether connecting, disconnecting or reconnecting design moments.

The role of improvisation in design thinking is central in creative processes that are constituted of thinking and feeling, action and making within complex environments in which designer-makers connect or disconnect steps and moments, thinking and feeling their ways through in multidirectional ways [1]. In the four design thinking moments, invention, judgement, connection and development, integration and evaluation [17], the role of improvisation in design processes is to connect and disconnect these four design thinking moments $[1,15]$. To connect and disconnect enables flexibility and variety despite complexities experienced within a given environment. In other words, to become 'unstuck' [18].

\subsection{Improvisation in Art-based Processes}

In art-based research and academic narrative improvisation is often overlooked as a process, except in music, dance and drama. Improvisation and its applications should thus be understood beyond the clichéd comparison to jazz [19]. More recently, improvisation is acknowledged as a means for stimulating user-centered participation in service design and organizational development $[15,16,20]$. Design processes are overshadowed by academic discussions that focus on innovation while the role of improvisation is often overlooked [1]. This notion results in the use of innovation as a shallow and over-used concept, often lacking applicability [Miettinen, personal conversation].

Improvisation is linked to the arts as it offers potential for creative, new and unique outcomes, whilst 'improvisers are more interest in processes of creation than in its products' [21]. Improvisation is associated with cognitive creativity and research-led practices in creative arts [22]. These practices are explained by the Gene-plore Model (generate and explore) [23], which is based on reiterative, associative and/or interruptive continuity and cycles of generation, exploration, refinement and selection [22]. Improvisation is often at the core of practice-based and participatory design, permitting artists and designers to be flexible, negotiate, take risks, unmake and remake processes. Improvisation as a tool for supporting design work [20], yet in this paper improvisation is rather introduced as a key ingredient in design processes, those crucial moments in which the improviser draws on intuitive action [24], enabling connectivity and continuity in complex processes to negotiate complexities.

\subsection{Interview Data: Learning from experience, thus gaining experience}

Elements of experimentation, risk taking and openness to change, which is an essential ingredient for improvisation and working through artefact making processes, was present in the narratives of the artist-designers interviewed in 2011 [25]. One participant reflects:

'I really wanted to do more of that. Experimenting and just coming up with new ideas all the time. I always try to involve myself in fashion shows and exhibitions and every time I learn. Every time. You don't realise what you're going to get from a certain experience.' (Participant, Windhoek 2011)

Experimentalism refers to unfinalised and untried techniques and ideas, but also invention. Improvisers take bold next steps by embracing uncertainties and believing in their skills and experiences to invest in risks [4]. The participant is willing to journey via multidirectional avenues to discover new outcomes, solve design problems, grow their practices as the participant illustrates. She prefers open-ended processes, creating artefacts through discovery and seeking out new experiences. Improvisers are able to think on their feet, with flexibility and agility, navigating the unknown [26].

'I'll take it, but play around with it to come up with something different. So I'll improvise by maybe asking a craftsperson or buying certain crafts that they make and try to take them apart maybe half way and then reuse them, but in a different way. I wanted 
to make this garment for a certain client and she wanted lots of beading on it and I didn't have time, so I had to improvise again. I looked around and I took a necklace, I actually bought three of them, attached them to the garment. So I save time, but I had to improvise at the same time to save time.' (Participant, Windhoek 2011)

Thrift refers to the value of being careful, or not wasteful, with resources, while resourcefulness refers to ingenuity in overcoming complexities or difficulties. Both the concepts of thrift and resourcefulness are underpinned by improvisatory approaches which are driven by a motivation for discovery. The participant works through the possibilities to be 'different' and thrifty simultaneously due to the pressing demands of clients and limited resources. She needs to save time with the aim to complete pressing tasks on time. Within improvisation's particular temporal dimensions, memories, intentions and intuition are combined [24].

'I enjoyed the whole process of trying to do something from nothing. And sometimes it's not how you imagined it, but you work with it and come to a solution or the solution.' (Participant, Windhoek 2011)

Improvisers recognize promisingness in their immediate environments and the limited resources at hand, thus avoiding waste [27]. Promisingness is solution-oriented while improvisation is accepting and transforming what is immediately available [26], while recognition is the identification of the known and is underpinned by social and cultural recognition which plays an important role in intuitive function during improvisatory processes. Improvisers have mastered working with what is 'there', the immediate resources available to them. Thereness refers to the given, immediate 'natural', social and cultural environments in which improvisers function in conjunction with their knowledge, processes and materials they have access to.

The participant acknowledged during the interview that her art and design practices usually include improvisatory processes and experimentation, because they allow creative expression. Her reflection on improvisation illustrates her positive attitude towards experimentation. Apart from intuition, improvisation responds to stimulus within the individual's environment [4,11]. Improvisation is an ongoing process of searching for new experiences, knowledge and enquiry that works by drawing on previously obtained knowledge and personal experiences [25]. In the participant's story, she reveals the moments during which she finds solutions to her design problems, which motivate her to continue these processes of learning, discovery and how to become unstuck. Importantly, she draws on environmental triggers to sustain her practice as she explains:

\begin{abstract}
'Now I can be fascinated about the colour and next time I can be fascinated by an object, or I can be fascinated by a print, depending on the moment. I try to work with it and I recreate. I don't know how the process starts, because it's ongoing. I always search for something, but using my environment, my surrounding and then from that I try to reinterpret something or try to come up with something that is new.' (Participant, Windhoek 2011)
\end{abstract}

The participant's story illustrates how stimuli in her environment inspire her to learn from her experiences while her newly gained experiences will fuel future improvisatory processes. It is understood as a deviation from the original or best plan [4]. However, the participant does not perceive working in such a fashion as makeshift or the second-best solution. This is what she does and 'the way [she] work[s]' [28]. Connected to her intuition, she sees and recognizes when something 'works', illustrated by the clever way she negotiates her processes. The value of improvisatory processes in art and design is that it acknowledges the role of flexibility, change, and multidirectionality, while drawing on practitioners' experiences, intuition and knowing in action, to guide working processes when becoming unstuck $[18,1]$.

Participants reap emotional rewards from their creative practices as well as their lecturing and training activities in Namibian art and design worlds. Some of the participants have worked with several rural craft-producing groups, sharing their skills in art and design in attempts to broaden their own and the communities' skills. The participants' creative practices formed the foundation of the knowledge they continue to share with the next generation of Namibian artists and designers and in this way, they not only sustain themselves emotionally and economically, but also contribute to the sustainability of Namibian art and design worlds. One participant shared the deep and significant meanings of these teaching and learning activities:

'Yes, it has been rewarding in a sense of you reach so many people. What I interpret as rewarding is, uhm, something that is worthwhile. A reward. I'd look at something like if I've made a contribution to, or if I've changed somebody's life I have really tried to make a difference somewhere.' (Participant, Windhoek 2011)

\subsection{Improvising through art-based practice: Personal reflections}

Fashion as an art form is not widely recognized, whereas textile practices and costume design for theatre is more commonly accepted as 'valid' forms of art. [Dunn, personal communication]. During my fashion career in Namibia (1994 - 2009) I presented fifty fashion collections on various international platforms. I also produced two 
exhibitions in collaboration with acclaimed Namibian photographer Amy Schoeman, inspired by the theme FotoFashionFusion in which works of photography and fashion presented powerful displays of art.

The exhibitions, presented at the National Arts Gallery of Namibia, were titled The Five Seasons (2003) and Eleven (2005). Eleven constituted the practical work for my master's degree in fashion design. Fashion performances were presented during both exhibitions' opening events. In both my bodies of work I based my making, cutting and textile techniques on the perceptible elements I recognized in Schoeman's photography. I reinterpreted the tactile and visible textures and colors detected in Schoeman's work through craft techniques such as sewing, fabric dyeing, felting, embroidery, wire work, knitting and beading, while textiles such as silk, lace, organza, chiffon and karakul felt were used to represent the textilities I sensed in her work.

My fashion practices were based on improvisation. Inspired by fine art (Shoeman's photography), I blended art and design practices, as well as crafts, to produce my collections. My planned designs were often supplemented by improvisation that happened in the spur of the moment [24]. Design processes involved rigorous yet careful planning, but I also needed the necessary flexibility offered by improvisation to connect moments of making within larger processes. Especially in moments where my next steps had to rely on my previous experiences and triggers deriving from my environment, the role of improvisation became pivotal in becoming unstuck.

Improvisers are problem solvers as they are "willing to break with the continuity of the old and new' [11]. When artefact makers become stuck they rely on breaking continuities [18], flexible thinking and action guided by experience and knowing through making [29, 30]. Improvisers cope with the limitations presented by the moment and the various resources available in their direct environments [11]. Due to limitations such as time, skilled seamstresses, quality materials, equipment and funding, I relied on previous experiences and the work traditions I had developed over almost two decades. I drew on intuition, the automatic emotional judgements of my experiences [2], and my 'specialist tacit knowing' [31]. This means that solutions to design problems were negotiated through a constant fighting against resource shortages and finding new ways of making within these boundaries. Limitations required of me an open mind, agility and adaptability [1]. At the same time, I was seeking out identity processes in a growing African fashion world.

The industrial-focused fashion production processes I learnt at a Technikon in South Africa were not appropriate for my situation. Although I gained a good foundation in fashion practices suitable for industrialized purposes, this knowledge was not transferable to a Namibian context, in which a couture-design focus was more appropriate due to the limited number and scale of garment factories.
Managing a small fashion production site with no more than seven employees, I had to adapt fast, relearning pattern cutting and fashion making techniques suited to individual garments and specifications without prior education in couture-design. Soon I realized that also my fashion practices were underpinned by rather unique art-based practices instead of rigidly innovated, well-designed and well-planned processes used in high-volume fashion factories.

Namibian university Fashion students faced similar realities in which they were, and still are, far removed from industrialized processes. In Namibia, tertiary education in fashion focuses on individualized and art-based fashion practices that are removed from commercial and industrial methods of production. These individual and art-based processes harbor a rich foundation for improvisatory processes for several reasons. Namibian education institutions and students constantly battle a lack of resources such as materials and equipment, while contact time with lecturers is limited to eight hours per week at the University of Namibia. Considering that students need to build skills in illustration, pattern design and garment construction, an allocation is hardly sufficient. As a result, students often practice in isolation, drawing on improvisation to become unstuck from the design problems.

When successful students continue to practice as self-starters in their new vocation after graduating, they continue improvisatory processes due to the continuing lack of resources. Thus, in conjunction with design, the creative practices of tertiary educated Namibian fashion designers rely on strong art-based, experimental and improvisatory processes. My ethnographic field study in Namibia illustrate that improvisation is a multidirectional process of making that is underpinned by experience, traditions and risk taking during experimentation.

\section{Conclusions}

Professional Namibian artists and designers usually draw on arts-based and improvised, rather than industrialized processes and mass-production in their practices. Design outcomes often overlap with fine arts, which also support empowerment and means of self-expression. Improvisation supports empowerment as Namibian artists and designers, who are usually distanced from industrial and Western ways of production and the latest design knowledge, find new ways of work through exploration, adaptability and agility to meet the demands of running sustainable art and design worlds. Improvisatory processes underpin Namibian art and design practice for several reasons: (a) to manage practices around limited resources to better sustain themselves, (b) as means to be 'different', thus negotiating identities and self-expression, (c) as means to be agile, adaptable and becoming unstuck. 


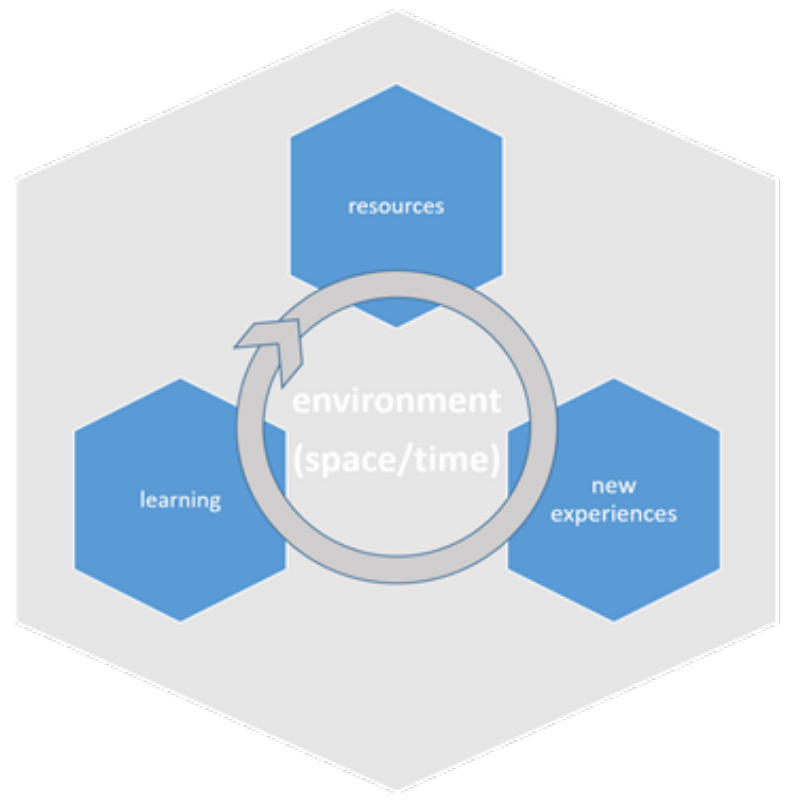

Diagram 2. A holistic approach to improvisation recognises the importance of the role of the environment on gaining new experiences and learning.

This paper explores the connective role of improvisation in design thinking moments. However, the connective role of improvisation can also be extended to lived experiences within environments in which complex processes unfold. To improvise is to connect new possibilities, thus creating flow [24,32]. Improvisatory action and processes can occur due to the recognition of affordances within environments. Affordances are relationships; actionable properties between individuals and their environments [33]. Environments can thus stimulate the shaping of new experiences through improvised processes when practitioners rely on their previous lived experiences to discover and learn.

The recognition of new resources within environments is possible through learning. In this way, lived experiences are enhanced and enriched. This improvised action creates multidirectional flow and the connection of processes, enhancing new experiences and learning, whilst guiding practitioners through uncertainties and complexities.

This diagram illustrates the holistic approach to improvisation that is based on actions within environments in which resources are utilized to solve design problems and build new experiences. In improvisatory processes, learning is stimulated through new experiences that come about by utilizing the available resources within a given environment. However, learning also enables the discovery of new resources and experiences, leading to increased resourcefulness and thriftiness.

\section{Acknowledgements}

The author acknowledges the financial support of Kone Foundation of Finland, the University of South Australia, and the Namibian Ministry of Education and Culture who made this research possible.

\section{REFERENCES}

[1] Sarantou, M.A., Miettinen, S.A. 2017. The connective role of improvisation in dealing with uncertainty during invention and design processes. Conference proceedings Research Perspectives on Creative Intersections. Design Management Academy, Hong Kong.

[2] Dunn, B. D., Galton, H. C., Morgan, R., Evans, D., Oliver, C., Meyer, M., ... \& Dalgleish, T. 2010. Listening to your heart: how interoception shapes emotion experience and intuitive decision making. Psychological science, 21(12), 1835-1844.

[3] Sadler-Smith, E., \& Shefy, E. (2007). Developing intuitive awareness in management education. Academy of Management Learning \& Education, 6(2), 186-205.

[4] Montuori, A. 2003. The complexity of improvisation and the improvisation of complexity: Social science, art and creativity. Human relations, 56(2), 237-255.

[5] Becker, H. S. 1976. "Art Worlds and Social Types." American Behavioral Scientist 19, no. 6: 703-718.

[6] Spradley, J. P. (2016). The ethnographic interview. Waveland Press.

[7] Ellis, C., Adams, T. E., \& Bochner, A. P. (2011). Autoethnography: an overview. Historical Social Research/Historische Sozialforschung, 273-290.

[8] Denshire, S. (2014). On auto-ethnography. Current Sociology, 62(6), 831-850.

[9] Charmaz, K. (2008). Constructionism and the grounded theory method. Handbook of constructionist research, $397-412$.

[10] Corbin, J. \& Strauss, A. (1990). Grounded Theory Research: Procedures, Canons, and Evaluative Qualitative Sociology, Vol. 13, No. 1, pp. 3-21.

[11] Peters, G. 2009. The Philosophy of Improvisation. Chicago: The University of Chicago Press.

[12] Jencks, C., \& Silver, N. (2013). Adhocism: the case for improvisation. Mit Press.

[13] Gustavsen, T. (1999). The dialectical eroticism of improvisation. Improvisation. Between technique and Spontaneity, 7-51.

[14] Lewis, G., \& Piekut, B. (Eds.). (2016). Introduction: On Critical Improvisation Studies. The Oxford Handbook of Critical Improvisation Studies, 1, 1-38. Oxford University Press.

[15] Secchi, E. 2012. "Essays on Service Improvisation Competence: Empirical Evidence from the Hospitality Industry". All Dissertations. Paper 999.

[16] John, J., Grove, S. J., \& Fisk, R. P. 2006. Improvisation in service performances: lessons from jazz. Managing Service 
Quality: An International Journal, 16(3), 247-268.

[17] Buchanan, R. 1992. Wicked problems in design thinking. Design issues, 8(2), 5-21.

[18] Hamdi, N. 2014. The Spacemaker's Guide to Big Change: Design and Improvisation in Development Practice. Routledge.

[19] Kamoche, K., \& Cunha, J. V. D. (2003). Towards a theory of organizational improvisation: Looking beyond the jazz metaphor. Journal of Management Studies, 40(8), 2023-2051.

[20] Gerber, E. 2007. Improvisation principles and techniques for design. In Proceedings of the SIGCHI conference on Human factors in computing systems, ACM, 1069-1072.

[21] Lewis, G., \& Piekut, B. (Eds.). (2016). Introduction: On Critical Improvisation Studies. The Oxford Handbook of Critical Improvisation Studies, 1, 1-38. Oxford University Press.

[22] Dean, R.T \& Bailes, F. (2016). Cognitive Processes in Musical Improvisation. The Oxford Handbook of Critical Improvisation Studies, 1, 39-58. Lewis, G., \& Piekut, B. (Eds.). Oxford University Press.

[23] Finke, R. A., Ward, T. B., \& Smith, S. M. (1992). Creative cognition: Theory, research, and applications.

[24] Nachmanovitch, S. 1990. Free play: Improvisation in life and art. New York: Penguin Putnam.

[25] Sarantou, M.A. 2014. Namibian narratives: Postcolonial identities in craft and design, Ph.D. Dissertation. University of South Australia, School of Art, Architecture and Design, South Australia.
[26] Leonard, K., and Yorton, T. (2015). Yes, And: How Improvisation Reverses "No, But" Thinking and Improves Creativity and Collaboration--Lessons from The Second City. Harper Collins.

[27] Chen, B., Scardamalia, M., Resendes, M., Chuy, M. and Bereiter, C., 2012. Students' intuitive understanding of promisingness and promisingness judgments to facilitate knowledge advancement. In The future of learning: Proceedings of the 10th international conference of the learning sciences (ICLS 2012) (Vol. 1, pp. 111-118).

[28] Ingold, T. \& Hallam, E. 2007. Creativity and cultural improvisation, Creativity and cultural improvisation, Hallam E. and Ingold T. (eds.), Oxford and New York, Berg, $1-24$.

[29] Kharitonova, M., Chien, S., Colunga, E., \& Munakata, Y. 2009. More than a matter of getting 'unstuck': flexible thinkers use more abstract representations than perseverators. Developmental Science, 12(4), 662-669.

[30] Cross, N. 1982. 'Designerly ways of knowing'. Design Studies, Vol 3, No 4, 221-227.

[31] Nimkulrat, N., Niedderer, K. \& Evans M. A. 2015. On Understanding Expertise, Connoisseurship, and Experiential Knowledge in Professional Practice. Journal of Research Practice, 11(2), 5-15.

[32] Csikszentmihalyi, M. (1996). Flow and the psychology of discovery and invention. New York: Harper Collins.

[33] Norman, D. A. (1999). Affordance, conventions, and design. Interactions, 6(3), 38-43. 